\title{
Predictive value of serum VEGF, IL-1 and TNF- $\alpha$ in the treatment of thromboangiitis obliterans by revascularization
}

\author{
ZHENG-FEI LI*, XIAO-JUN SHU*, WEN-HUI WANG, SHENG-YE LIU, \\ LEI DANG, YAN-QIANG SHI and YAN-WEN BAI
}

The Department of Interventional Radiology of The First Hospital of Lanzhou University, Lanzhou, Gansu 730000, P.R. China

Received May 10, 2019; Accepted January 20, 2020

DOI: $10.3892 / \mathrm{etm} .2020 .9362$

\begin{abstract}
Effect of revascularization in the treatment of thromboangiitis obliterans (TAO) and the predictive value of serum vascular endothelial growth factor (VEGF), interleukin-1 (IL-1) and tumor necrosis factor- $\alpha$ (TNF- $\alpha$ ) of risk factors of amputation were investigated. From April 2012 to August 2015, a total of 117 patients with TAO admitted to the First Hospital of Lanzhou University were selected. Patients treated with revascularization combined with prostaglandin sodium and cilostazol were enrolled in group A (67 patients), and patients treated with sodium and cilostazol were enrolled in group B (50 patients). The clinical efficacy was evaluated by calculating the intermittent claudication distance and the ankle brachial index (ABI) of patients. The occurrence probability of nausea and vomiting, skin pruritus, abdominal pain, coagulation abnormalities and amputation were recorded. The concentration of serum VEGF, IL-1 and TNF- $\alpha$ were measured using enzyme-linked immunosorbent assay (ELISA). After treatment, the intermittent claudication distance, ABI and efficiency of group A was markedly higher than that of group $\mathrm{B}(\mathrm{P}<0.05)$. After treatment, serum VEGF concentration in group A was clearly higher than that in group $\mathrm{B}(\mathrm{P}<0.05)$, and IL-1 and TNF- $\alpha$ levels were much lower than those in group $\mathrm{B}(\mathrm{P}<0.05)$. The amputation rate in group $\mathrm{A}$ was significantly lower than that in group $\mathrm{B}(\mathrm{P}<0.05)$. Patients with amputation in both groups were enrolled in the study group (24 cases), and those without amputation were included in the control group (93 cases). The serum VEGF concentration in the study group before treatment was significantly lower than that in the control group $(\mathrm{P}<0.05)$, while IL-1 and TNF- $\alpha$ levels were significantly higher than those of the control group $(\mathrm{P}<0.05)$.
\end{abstract}

Correspondence to: Dr Xiao-Jun Shu, The Department of Interventional Radiology of The First Hospital of Lanzhou University, 1 Donggang West Road, Lanzhou, Gansu 730000, P.R. China E-mail: shuxiaojun717@163.com

*Contributed equally

Key words: thromboangiitis obliterans, revascularization, clinical efficacy, prognosis
In conclusion, pretreatment serum VEGF, IL-1 and TNF- $\alpha$ had a positive diagnostic value for poor prognosis of patients with amputation, and low concentration of VEGF and higher concentration of IL-1 and TNF- $\alpha$ are the risk factors for amputations in patients with TAO.

\section{Introduction}

Thromboangiitis obliterans (TAO) is a non-atherosclerotic inflammatory disease of unknown etiology, usually affecting the small and medium arteries of the upper and lower limbs. Long-term smoking is closely related to the incidence of TAO (1). Epidemiology shows that TAO is distributed all over the world. The prevalence of peripheral arterial diseases can reach $16-66 \%$ in Korean and Japanese patients. For Indian patients the value can be as high as 45-63\%. In recent years, it has been shown that the prevalence of TAO in women has also increased, reaching $11-23 \%$ (2). Early TAO manifests as ischemic symptoms, and in the advanced stage, symptoms such as limb ulcers and gangrene appear (3). Although there is a detailed understanding of the occurrence and development of TAO, TAO has the characteristics of being difficult to cure clinically. This condition is concurrent to vascular reocclusion and eventually leads to amputation (4).

At present, the main treatment used for TAO includes drug therapy and revascularization. In these methods the medical team tries to enrich the collateral vessels, increase the blood supply of the limb ischemic area and reduce the blood viscosity $(5,6)$. Usually, antiplatelet and vasodilator drugs are used for the treatment of TAO, these includes 5-HT2 receptor antagonists, prostaglandins, and vascular endothelin-1 receptor antagonists. Prostaglandin sodium and cilostazol are the widely used medications due to their good efficiency on TAO $(7,8)$. There are also surgical treatment available to patients, such as endometrial ablation, vascular bypass, lumbar sympathectomy, balloon dilatation or catheter thrombolysis and amputation. Although a good clinical efficacy has been achieved, the specific effects of treating TAO are still controversial $(9,10)$.

The pathological manifestations of TAO are mainly the presence of white blood cells and inflammatory thrombus in the diseased vessel wall, and the end stage is often accompanied by fibrotic mature thrombus (11). The immune system 
and inflammatory response play an important role in the pathogenesis of TAO. The interaction between inflammation and hemostasis increases the tendency of thrombosis, and chronic inflammation can induce endothelial damage (12). Vascular endothelial growth factor (VEGF) is an endogenous angiogenic growth factor that acts on vascular endothelial cells and promotes vascular growth and endothelial proliferation (13). VEGF has an effect on limb ischemia caused by TAO and may play an important role in the occurrence, development and treatment of TAO (14). Interleukin-1 (IL-1) can regulate the expression of various growth factors and inflammatory factors, and its expression in vascular injury is elevated, which plays an important role in the development of vascular injury (15). Tumor necrosis factor- $\alpha$ (TNF- $\alpha$ ) is an inflammatory cytokine promoting thrombus formation by inducing macrophage/monocyte expression (16). Previous studies have shown that TNF- $\alpha$ may be involved in the pathological process of TAO (17).

Clinical treatment of TAO is still controversial (18). In this study, patients with TAO were treated with revascularization combined with drugs to observe the clinical efficacy of the treatment and to evaluate the therapeutic and prognostic role of VEGF, IL-1 and TNF- $\alpha$ in TAO.

\section{Patients and methods}

General materials. A total of 117 patients with TAO admitted to the First Hospital of Lanzhou University (Lanzhou, China) from April 2012 to August 2015 were selected for this study. Patients treated with revascularization combined with prostaglandin sodium and cilostazol were included in group A (67 patients), and patients treated with sodium and cilostazol were enrolled in group B (50 patients). There were 63 males and 4 females in group A, the age range was $46-69$ years, mean age $55.3 \pm 8.6$ years, and mean disease duration was $3.8 \pm 1.2$ years. We had 36 cases of unilateral lesions of lower extremities and 31 cases of bilateral lesions of lower limbs. In group B, there were 48 males and 2 females, the age range was $45-67$ years, and mean age was $54.7 \pm 9.4$ years. There were 29 cases of unilateral lesions of lower extremities and 21 cases of bilateral lesions of lower limbs. All enrolled patients understood the study and signed an informed consent form. This study program was submitted to the Ethics Committee of the First Hospital of Lanzhou University for review and was implemented after the approval was obtained.

Inclusion and exclusion criteria. Inclusion criteria: Confirmed as TAO by limb angiography; age between 44 to 70 years; Buerger test (19) was positive; clinical data were complete. Patients in both groups were treated with prostate sodium and cilostazol on the same day.

Exclusion criteria: Anti-inflammatory and immunosuppressive drugs had been used in the past month; allergic to this drug; surgical related contraindications; combined with severe liver and kidney dysfunction, arteriosclerosis obliterans, acute arterial embolism, hematopoietic dysfunction, malignant tumors, endocrine systemic diseases, diabetic gangrene, mental diseases; severe tissue necrosis and limb infections.

Treatment. Group B was given IV infusion of alprostadil $10 \mu \mathrm{g}$ (Beijing Tide Pharmaceutical Co., Ltd., batch no. H10980024) in $0.9 \%$ sodium chloride injection $(100 \mathrm{ml})$, once a day for 2 weeks. Cilostazol tablets (Shandong Lukang Pharmaceutical Group Saite Co., Ltd., batch no. H20054770) were given orally, twice a day for long-term, each oral dose was $100 \mathrm{mg}$. Patients in group A underwent revascularization, 45 patients underwent thrombolysis and balloon angioplasty. Twenty-two patients underwent vascular bypass surgery, and after the surgery low-molecular-weight heparin $0.4 \mathrm{ml}$ was injected subcutaneously. The follow-up treatment was consistent with group B.

Arterial interventional angioplasty: Continuous epidural anesthesia was performed, and the ipsilateral femoral artery was punctured antegradely to perform a 'turning over the mountain' approach. Limb angiography was used to confirm the location of the lesion, the inflow and outflow tract, and degree. $5 \mathrm{~F}$ catheter was used to dredge the occlusion artery under the guidance of the circuit diagram, then followed the catheter to dredge the lesion segment to the distal artery of the lesion. We confirmed that the distal end of the catheter was located in the true lumen of the vessel, and introduced a balloon with a diameter of $2.5 \mathrm{~mm}$ to expand occlusive vessel from the distal end to the proximal end. The superficial femoral artery or the aplicular artery were often expanded with a $4.0 \mathrm{~mm}$ balloon.

Vascular bypass surgery: a continuous epidural anesthesia was performed by dissociating the great saphenous vein trunk, followed by a ligature of the great saphenous vein branch. The proximal and distal end of the great saphenous vein was then cut and ligatured. The proximal end was inserted with a thin tube, which was used for injection of physiological saline, and the upper part of the valve was pressurized, to assure that the physiological saline would flow out from the distal end of the great saphenous vein along the proximal end. The posterior tibial artery was exfoliated from the anterior tibial muscle layer, and the artificial blood vessel patch or the autologous great saphenous vein surgery was performed. Then, the upper and lower great saphenous veins were anastomosed to the common femoral artery and posterior tibial artery.

Determination of efficacy. After 3 months of treatment, the curative effect was evaluated. Healed: Normal walking $2.0 \mathrm{~km}$ without discomfort, skin temperature and skin color improved obviously or returned to normal, limp, rest pain and gangrene improved markedly or disappeared, wound healing was good, distal arterial pulsation is fully restored. Markedly effective: Normal walking $0.5 \mathrm{~km}$ without discomfort, skin temperature, skin color and ischemic symptoms improved, wound surface narrowed, distal arterial pulsation partially recovered. Effective: Feeling uncomfortable after walking $300 \mathrm{~m}$, body often feels numb, and skin temperature, skin color and ischemic symptoms are alleviated. Ineffective: Failure to walk normally, skin temperature, skin color and ischemic symptoms did not improve or worsen. (Healed + markedly effective + effective)/total number of cases $\times 100 \%=$ treatment effective rate.

Observation indicators. The intermittent claudication distance was observed before the surgery and 6 months after surgery. The patient walked at a constant speed and recorded 
the distance traveled until the affected limb was forced to stop due to pain. The ES-100V3 Doppler blood flow detector (Changsha Tengjian Medical Devices Co., Ltd.) was used to detect the ankle brachial index (ABI), and the blood flow waveform and contraction of the bilateral brachial artery and foot dorsal artery were measured. The peak of bilateral brachial artery systolic pressure was brachial artery pressure, and the middle systolic pressure of foot dorsal artery was ankle artery pressure. The ankle artery pressure was divided by the brachial artery pressure in order to calculate the ABI value. Patients were recorded for 12 months for presence of nausea and vomiting, skin pruritus, abdominal pain, and coagulation abnormalities. Patients were followed up once a year for 3 years in order to record the occurrence of amputation. Patients with amputation in both groups were enrolled in the study group, and those without amputation were included in the control group.

Detection method. Venous blood samples $(5 \mathrm{ml})$ were collected before and 1 month after the beginning of the treatment. Serum VEGF, IL-1 and TNF- $\alpha$ levels were evaluated using enzyme-linked immunosorbent assay (ELISA), referring to human VEGF, IL-1 and TNF- $\alpha$ ELISA (Shanghai Hengfei Biotechnology Co., Ltd., CSB-E11718h-1, CSB-E04620h-1, 130-094-023) instructions. The sample and the kit were equilibrated for $30 \mathrm{~min}$. Fifty microliters of the standard was added to the standard well, and $50 \mu 1$ of the sample was added to the sample well. Fifty microliters of streptavidin-HRP was the added and wells were covered with sealing film. Plates were incubated at $37^{\circ} \mathrm{C}$ for $60 \mathrm{~min}$, and after the incubation period all liquids were discarded, and wells were rinsed (5 times). Reagents A and B were added to each well (50 $\mu \mathrm{l})$, and plates were incubated at $37^{\circ} \mathrm{C}$ for $10 \mathrm{~min}$ in the dark. Fifty microliters of the stop solution was then added to each well, and the OD value was read at a wavelength of $450 \mathrm{~nm}$ using a Biotek automatic microplate reader (Shanghai Biyou Biotechnology Co., Ltd.), and the concentrations of VEGF, IL-1 and TNF- $\alpha$ were calculated.

Statistical methods. Statistical analysis was performed using SPSS 20.0 (IBM Corp). The count data were expressed as the number/count percentage (n/\%). Chi-square test was used to compare the count data between groups. When the theoretical frequency in the Chi-square test was less than 5, the continuity correction Chi-square test was used. Measurement data were expressed as mean \pm standard deviation (mean $\pm \mathrm{SD}$ ). The t-test was used to compare the measurement data between groups, and paired t-test was used to compare that before and after treatment. Risk factors were analyzed by Logistic multivariate regression analysis. $\mathrm{P}<0.05$, indicates the difference is statistically significant.

\section{Results}

General materials of the two groups. There were no significant differences in general clinical data between the groups. General clinical data included sex, age, body mass index (BMI), duration of disease, smoking history, drinking history, hypertension, erythrocyte sedimentation rate (ESR), lesion site, and ischemic staging $(\mathrm{P}>0.05)$ (Table I).
Intermittent claudication distance and $A B I$ before and after treatment in the two groups. There was no significant difference in the intermittent claudication distance and ABI between groups before treatment $(\mathrm{P}>0.05)$. After treatment, the intermittent claudication distance and ABI in both groups were significantly higher than those measured before treatment $(\mathrm{P}<0.05)$. After treatment, the intermittent claudication distance and $\mathrm{ABI}$ in group $\mathrm{A}$ were significantly higher than those in group $\mathrm{B}(\mathrm{P}<0.05)$ (Table II).

Effective treatment rate of the two groups. Effective rate in group A was $95.52 \%$. Nineteen cases (28.36\%) were fully healed, treatment in 33 cases $(49.25 \%)$ were markedly effective, 12 cases $(17.91 \%)$ were effective, 3 cases $(4.48 \%)$ were ineffective, and the effective treatment rate was $95.52 \%$. Effective treatment rate in group B was $84.00 \%$. Nine cases were fully healed $(18.00 \%), 15$ cases $(30.00 \%)$ were markedly effective, 18 cases $(36.00 \%)$ were effective, and 8 cases $(16.00 \%)$ were ineffective. The effective treatment rate of group A was significantly higher than that of group $\mathrm{B}(\mathrm{P}<0.05)$ (Table III).

Changes of serum VEGF, IL-1 and TNF- $\alpha$ concentrations before and after treatment in the two groups. There was no significant difference in serum VEGF, IL-1 and TNF- $\alpha$ levels between groups before treatment $(\mathrm{P}>0.05)$. After treatment, serum VEGF levels in both groups were both obviously higher than those before treatment $(\mathrm{P}<0.05)$. IL-1 and TNF- $\alpha$ levels were significantly declined $(\mathrm{P}<0.05)$. After treatment, serum VEGF level in group A was distinctly higher than that in group $\mathrm{B}(\mathrm{P}<0.05)$, and IL-1 and TNF- $\alpha$ levels were noticeably lower than those in group $\mathrm{B}(\mathrm{P}<0.05)$ (Table IV and Fig. 1).

Adverse reactions and amputation rate of the two groups. In group A, there were 3 cases $(4.48 \%$ ) with nausea and vomiting, 1 case $(1.49 \%)$ with skin pruritus, 2 cases $(2.99 \%)$ with abdominal pain, 2 cases $(2.99 \%$ ) with coagulation abnormality, and 9 cases $(13.43 \%)$ with amputation. In group B, there were 2 cases $(4.00 \%)$ with nausea and vomiting, 1 case $(2.00 \%)$ with skin pruritus, 1 case $(2.00 \%)$ with coagulation abnormality, and 15 cases $(30.00 \%)$ with amputation. There was no significant difference in the incidence of nausea and vomiting, skin pruritus, abdominal pain, coagulation abnormality and amputation between groups $(\mathrm{P}>0.05)$. The amputation rate in group $\mathrm{A}$ was significantly lower than that in group $\mathrm{B}(\mathrm{P}<0.05)$ (Table V).

Diagnostic value of serum VEGF, IL-1 and TNF- $\alpha$ levels before treatment for amputation. Patients with amputation in both groups (24 cases) were enrolled in the study group, and those without amputation were included in the control group (93 cases). Before treatment, the concentrations of serum VEGF, IL-1 and TNF- $\alpha$ were $5.04 \pm 0.53,9.15 \pm 1.37$, $5.23 \pm 0.78 \mathrm{ng} / \mathrm{l}$ in the study group, and $5.72 \pm 0.79,8.21 \pm 1.36$, $4.35 \pm 0.64 \mathrm{ng} / 1$ in the control group, respectively. The serum VEGF level in the study group before treatment was significantly lower than that in the control group $(\mathrm{P}<0.05)$, while the levels of IL-1 and TNF- $\alpha$ were markedly higher than those of the control group $(\mathrm{P}<0.05)$. The ROC curve prognosis of amputation was evaluated in patients with TAO by pretreatment serum VEGF, IL-1 and TNF- $\alpha$ levels. The most appropriate cutoff was determined, taking sensitivity 
Table I. General materials of group A and group B $[\mathrm{n}(\%)]($ mean $\pm \mathrm{SD})$.

\begin{tabular}{|c|c|c|c|c|}
\hline Category & Group A $(n=67)$ & Group B $(n=50)$ & $\mathrm{t} / \chi^{2}$ value & P-value \\
\hline Sex & & & 0.228 & 0.633 \\
\hline Male & $63(94.03)$ & $48(96.00)$ & & \\
\hline Female & $4(5.97)$ & $2(4.00)$ & & \\
\hline Age (years) & $55.3 \pm 8.6$ & $54.7 \pm 9.4$ & 0.359 & 0.720 \\
\hline $\operatorname{BMI}\left(\mathrm{kg} / \mathrm{m}^{2}\right)$ & $23.2 \pm 2.4$ & $23.6 \pm 2.5$ & 0.876 & 0.383 \\
\hline Duration (year) & $3.8 \pm 1.2$ & $3.6 \pm 1.4$ & 0.830 & 0.408 \\
\hline Smoking history & & & 0.632 & 0.427 \\
\hline Yes & 64 (95.52) & $46(92.00)$ & & \\
\hline No & $3(4.48)$ & $4(8.00)$ & & \\
\hline Drinking history & & & 0.400 & 0.527 \\
\hline Yes & $59(88.06)$ & $42(84.00)$ & & \\
\hline No & $8(11.94)$ & $8(16.00)$ & & \\
\hline Hypertension & & & 0.037 & 0.848 \\
\hline Yes & $6(8.96)$ & $5(10.00)$ & & \\
\hline No & $61(91.04)$ & $45(90.00)$ & & \\
\hline $\operatorname{ESR}(\mathrm{mm} / \mathrm{h})$ & & & 0.025 & 0.873 \\
\hline$\geq 30$ & $10(14.93)$ & $8(16.00)$ & & \\
\hline$<30$ & $57(85.07)$ & $42(84.00)$ & & \\
\hline Lesion site & & & 0.211 & 0.646 \\
\hline Unilateral lower limb & $36(53.73)$ & $29(58.00)$ & & \\
\hline Bilateral lower limbs & $31(46.27)$ & $21(42.00)$ & & \\
\hline Ischemic staging & & & 2.613 & 0.271 \\
\hline Ischemic period (stage I) & $28(41.79)$ & $27(54.00)$ & & \\
\hline Nutritional disorder period (stage II) & $26(38.81)$ & $18(36.00)$ & & \\
\hline Tissue necrosis period (stage III) & $13(19.40)$ & $5(10.00)$ & & \\
\hline
\end{tabular}

Table II. Comparison of intermittent claudication distance and ABI before and after treatment in group A and group B (mean \pm SD).

\begin{tabular}{|c|c|c|c|c|c|c|c|c|c|}
\hline \multirow[b]{2}{*}{ Group } & \multirow[b]{2}{*}{$\mathrm{n}$} & \multicolumn{2}{|c|}{$\begin{array}{l}\text { Intermittent claudication } \\
\text { distance }(\mathrm{km})\end{array}$} & \multirow[b]{2}{*}{$\mathrm{t}$ value } & \multirow[b]{2}{*}{ P-value } & \multicolumn{2}{|c|}{$\mathrm{ABI}$} & \multirow[b]{2}{*}{$\mathrm{t}$ value } & \multirow[b]{2}{*}{ P-value } \\
\hline & & $\begin{array}{l}\text { Before } \\
\text { treatment }\end{array}$ & $\begin{array}{c}\text { After } \\
\text { treatment }\end{array}$ & & & $\begin{array}{l}\text { Before } \\
\text { treatment }\end{array}$ & $\begin{array}{c}\text { After } \\
\text { treatment }\end{array}$ & & \\
\hline Group A & 67 & $0.21 \pm 0.09$ & $2.42 \pm 0.51$ & 34.930 & $<0.001$ & $0.41 \pm 0.10$ & $0.84 \pm 0.16$ & 18.650 & $<0.001$ \\
\hline Group B & 50 & $0.23 \pm 0.08$ & $2.13 \pm 0.43$ & 30.720 & $<0.001$ & $0.39 \pm 0.11$ & $0.76 \pm 0.13$ & 15.360 & $<0.001$ \\
\hline $\mathrm{t}$ value & - & 1.246 & 3.249 & - & - & 1.025 & 2.893 & - & - \\
\hline P-value & - & 0.215 & 0.002 & - & - & 0.307 & 0.005 & - & - \\
\hline
\end{tabular}

and specificity into account. The AUC value of pretreatment serum VEGF level to determine the need for amputation in TAO patients was 0.709 , the sensitivity was $79.17 \%$, the specificity was $58.06 \%$, and the cutoff was $5.78 \mathrm{ng} / \mathrm{l}$. AUC value of pretreatment serum IL-1 level to determine the need for amputation in TAO patients was 0.727 , the sensitivity was $83.33 \%$, the specificity was $59.14 \%$, and the cutoff was $9.17 \mathrm{ng} / \mathrm{l}$. The AUC value of pretreatment serum TNF- $\alpha$ concentration to determine the need for amputation in TAO patients was 0.741 , the sensitivity was $83.33 \%$, the specificity was $60.22 \%$, and the cutoff was $5.08 \mathrm{ng} / \mathrm{l}$ (Table VI and Fig. 2).

Analysis of risk factors affecting amputation in patients with $T A O$. Logistic multivariate analysis of risk factors for amputation in patients with TAO showed that sex, age, BMI, duration of disease, drinking history, hypertension, ESR, and lesion site were not associated with amputation in TAO patients $(\mathrm{P}>0.05)$. Smoking history, ischemic staging, revascularization, VEGF, IL-1 and TNF- $\alpha$ were independent risk factors for amputation 
Table III. Comparison of treatment effective rate between group A and group B [n(\%)].

\begin{tabular}{lcccccc}
\hline Group & $\mathrm{n}$ & Healed & Markedly effective & Effective & Ineffective & Effective treatment rate $(\%)$ \\
\hline Group A & 67 & $19(28.36)$ & $33(49.25)$ & $12(17.91)$ & $3(4.48)$ & 95.52 \\
Group B & 50 & $9(18.00)$ & $15(30.00)$ & $18(36.00)$ & $8(16.00)$ & 84.00 \\
$\chi^{2}$ value & - & - & - & - & - & 4.463 \\
P-value & - & - & - & - & 0.035 \\
\hline
\end{tabular}

Table IV. Comparison of serum VEGF, IL-1 and TNF- $\alpha$ concentrations before and after treatment in group A and group B $($ mean $\pm \mathrm{SD})$.

\begin{tabular}{|c|c|c|c|c|}
\hline Category & Group A $(n=67)$ & Group B $(n=50)$ & $\mathrm{t}$ value & $\mathrm{P}$-value \\
\hline \multicolumn{5}{|l|}{ VEGF (ng/l) } \\
\hline Before treatment & $5.44 \pm 0.93$ & $5.49 \pm 0.85$ & 0.298 & 0.766 \\
\hline After treatment & $7.35 \pm 1.02$ & $6.16 \pm 0.97$ & 6.462 & $<0.001$ \\
\hline t value & 15.150 & 8.492 & - & - \\
\hline P-value & $<0.001$ & $<0.001$ & - & - \\
\hline \multicolumn{5}{|l|}{ IL-1 (ng/l) } \\
\hline Before treatment & $8.49 \pm 1.25$ & $8.36 \pm 1.19$ & 0.568 & 0.571 \\
\hline After treatment & $5.83 \pm 1.02$ & $6.58 \pm 0.93$ & 4.084 & $<0.001$ \\
\hline t value & 13.500 & 8.334 & - & - \\
\hline P-value & $<0.001$ & $<0.001$ & - & - \\
\hline \multicolumn{5}{|l|}{ TNF- $\alpha(n g / l)$} \\
\hline Before treatment & $4.51 \pm 0.87$ & $4.42 \pm 0.95$ & 0.559 & 0.577 \\
\hline After treatment & $2.93 \pm 0.51$ & $3.68 \pm 0.57$ & 7.482 & $<0.001$ \\
\hline $\mathrm{t}$ value & 12.820 & 5.113 & - & - \\
\hline P-value & $<0.001$ & $<0.001$ & - & - \\
\hline
\end{tabular}

VEGF, vascular endothelial growth factor; IL-1, interleukin-1; TNF- $\alpha$, tumor necrosis factor- $\alpha$.

Table V. Comparison of adverse reactions and complications between group A and group B [n(\%)].

\begin{tabular}{|c|c|c|c|c|}
\hline Category & Group A $(n=67)$ & Group B $(n=50)$ & $\chi^{2}$ value & $\mathrm{P}$-value \\
\hline Nausea and vomiting & $3(4.48)$ & $2(4.00)$ & 0.016 & 0.899 \\
\hline Skin pruritus & $1(1.49)$ & $1(2.00)$ & 0.044 & 0.834 \\
\hline Abdominal pain & $2(2.99)$ & $0(0.00)$ & 1.518 & 0.218 \\
\hline Coagulation abnormality & $2(2.99)$ & $1(2.00)$ & 0.111 & 0.739 \\
\hline Amputation & $9(13.43)$ & $15(30.00)$ & 4.820 & 0.028 \\
\hline
\end{tabular}

in TAO patients $(\mathrm{P}<0.05)$. Low concentration of VEGF and high concentration of IL-1 and TNF- $\alpha$ were risk factors for amputation (Table VII).

\section{Discussion}

TAO has a variety of clinical treatment methods, such as antiplatelet drugs, anticoagulants, and vasodilators, although there is no evidence that they have a palliative effect (20). Prostaglandin analogues are also beneficial in the treatment of TAO, but there are still some inadequacies in recent effects. Revascularization, sympathectomy, Ilicavor technique and autologous omental fixation are still controversial in the treatment of TAO (21).

Revascularization includes vascular bypass grafting and percutaneous transluminal angioplasty (22). Vascular bypass grafting is widely used in atherosclerotic diseases. Artificial blood vessels or autologous blood vessels are used for bridging at the site of diseased blood vessels, thereby improving the blood circulation of tissues (23). Balloon dilatation and stent implantation are important methods for percutaneous transluminal angioplasty, with the characteristics of minimal trauma, safety, and exact curative effect. However, these methods are limited by the distal outflow tract and may cause reocclusion 
A

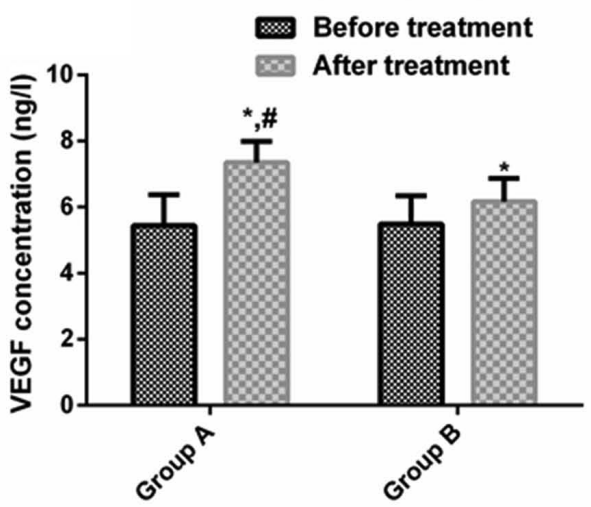

B

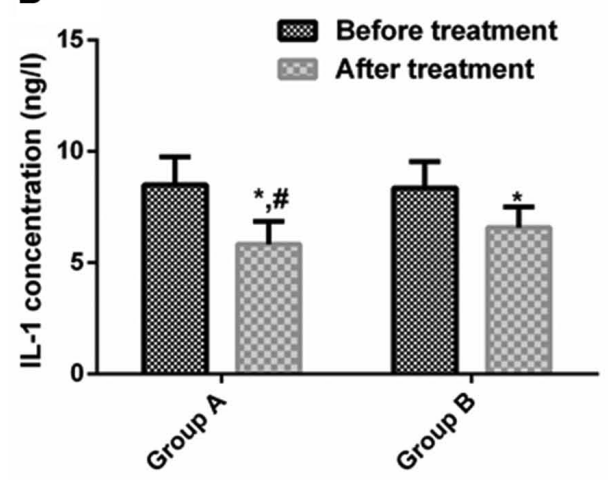

C

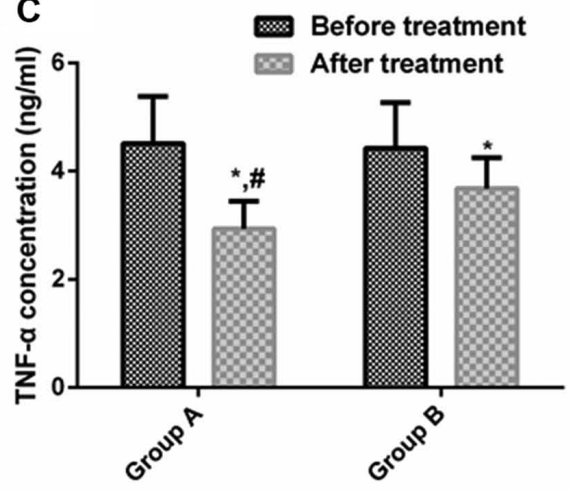

Figure 1. Comparison of serum VEGF, IL-1 and TNF- $\alpha$ concentrations before and after treatment in group A and group B. (A) Comparison of serum VEGF concentrations before and after treatment. (B) Comparison of serum IL-1 concentrations before and after treatment. (C) Comparison of serum TNF- $\alpha$ concentrations before and after treatment. $\mathrm{P}<0.05$ compared with control group; ${ }^{\#} \mathrm{P}<0.05$ compared with group $\mathrm{B}$. VEGF, vascular endothelial growth factor; IL-1, interleukin-1; TNF- $\alpha$, tumor necrosis factor- $\alpha$.

A
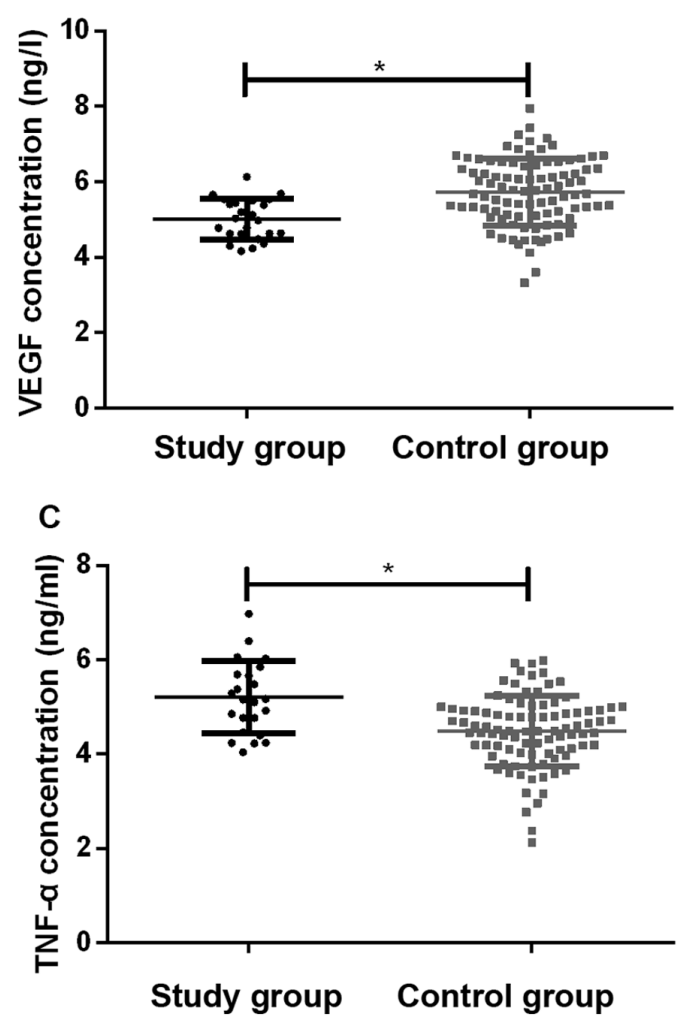

B

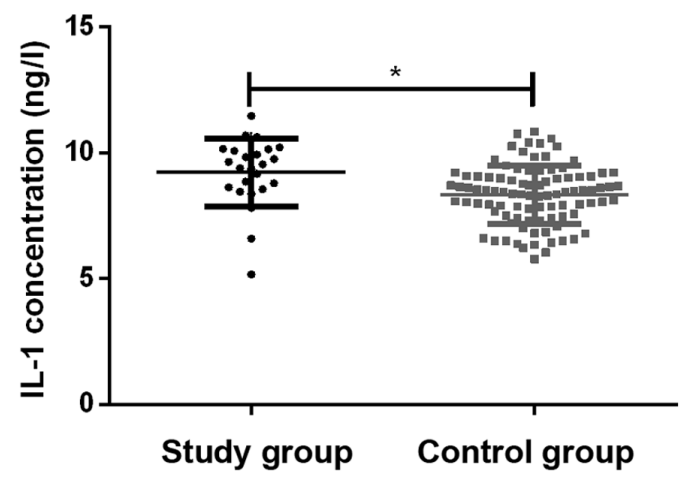

D

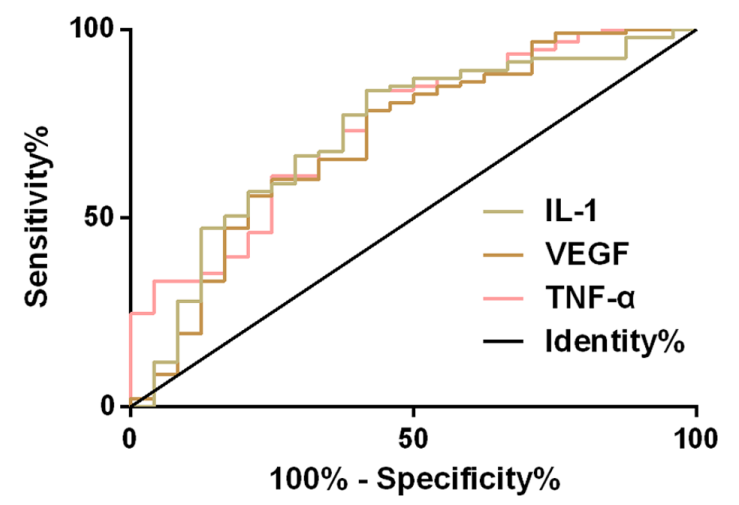

Figure 2. Diagnostic value of serum VEGF, IL-1, TNF- $\alpha$ concentrations in the study group and the control group before treatment for amputation. (A) VEGF concentrations in both groups. (B) IL-1 concentrations in both groups. (C) TNF- $\alpha$ concentrations in both groups. (D) Diagnostic value of serum VEGF, IL-1, TNF- $\alpha$ for amputation. ${ }^{*} \mathrm{P}<0.05$ compared with control group. VEGF, vascular endothelial growth factor; IL-1, interleukin-1; TNF- $\alpha$, tumor necrosis factor- $\alpha$. 
Table VI. Diagnostic value of serum VEGF, IL-1 and TNF- $\alpha$ concentrations before treatment for amputation in patients with TAO.

\begin{tabular}{lcccccc}
\hline Diagnostic indicator & AUC & $95 \%$ CI & Std. Error & Cut-off (ng/l) & Sensitivity (\%) & Specificity (\%) \\
\hline VEGF & 0.709 & $0.583-0.835$ & 0.064 & 5.78 & 79.17 & 58.06 \\
IL-1 & 0.727 & $0.607-0.847$ & 0.061 & 9.17 & 83.33 & 59.14 \\
TNF- $\alpha$ & 0.741 & $0.629-0.523$ & 0.057 & 5.08 & 83.33 & 60.22 \\
\hline
\end{tabular}

VEGF, vascular endothelial growth factor; IL-1, interleukin-1; TNF- $\alpha$, tumor necrosis factor- $\alpha$; TAO, thromboangiitis obliterans.

Table VII. Logistic multivariate analysis of risk factors for amputation in patients with TAO.

\begin{tabular}{|c|c|c|c|c|c|c|}
\hline Variable & Regression coefficients & Standard error & Wald value & $\mathrm{P}$-value & OR value & $95 \% \mathrm{CI}$ \\
\hline Sex & 0.070 & 0.167 & 0.173 & 0.675 & 1.072 & $0.774-1.483$ \\
\hline Age (years) & 0.433 & 0.407 & 1.131 & 0.287 & 1.541 & $0.694-3.423$ \\
\hline BMI & 0.058 & 0.034 & 3.030 & 0.083 & 1.061 & $0.994-1.132$ \\
\hline Duration & 1.273 & 0.726 & 4.348 & 0.184 & 0.843 & $1.131-4.476$ \\
\hline Smoking history & 1.521 & 0.391 & 15.183 & $<0.001$ & 4.573 & $2.129-9.823$ \\
\hline Drinking history & 0.059 & 0.033 & 3.030 & 0.083 & 1.060 & $0.994-1.132$ \\
\hline Hypertension & 1.335 & 0.703 & 3.548 & 0.060 & 3.798 & $0.948-15.216$ \\
\hline ESR & 1.089 & 0.598 & 3.328 & 0.068 & 2.972 & $0.923-9.576$ \\
\hline Lesion site & 2.723 & 0.562 & 6.462 & 0.097 & 0.514 & $1.461-3.473$ \\
\hline Ischemic staging & 1.118 & 0.373 & 9.057 & $<0.001$ & 3.062 & $1.478-6.345$ \\
\hline Revascularization & 0.439 & 0.227 & 6.579 & $<0.001$ & 3.569 & $1.346-2.357$ \\
\hline VEGF & 0.345 & 0.166 & 4.273 & 0.038 & 1.412 & $1.018-1.957$ \\
\hline IL-1 & 0.781 & 0.347 & 5.083 & 0.026 & 2.183 & $1.108-4.305$ \\
\hline TNF- $\alpha$ & 0.882 & 0.391 & 4.871 & 0.026 & 2.416 & $1.105-5.283$ \\
\hline
\end{tabular}

VEGF, vascular endothelial growth factor; IL-1, interleukin-1; TNF- $\alpha$, tumor necrosis factor- $\alpha$; ESR, erythrocyte sedimentation rate; TAO, thromboangiitis obliterans.

of the diseased vessel (20). In the study of Dilege et al (24), vascular bypass grafting was performed on TAO, and the patency rates of 1,2 , and 3 years after surgery were 59.2, 48.0 and $33.3 \%$. The patency rate decreased with time. Therefore, the long-term efficacy of revascularization is questionable. In the study of Bozkurt et al (25), the 4-week effective rate of prostacyclin in treating TAO patients was $61.9 \%$, and the effective rate was up to $85.3 \%$ with time. TAO was treated with revascularization and supplemented with alprostadil and cilostazol tablets. The results showed that the intermittent claudication distance and ABI in both groups increased significantly after treatment, and the intermittent claudication distance, $\mathrm{ABI}$, and effective treatment rate in group A were obviously higher than those in group B. The amputation rate in group A was significantly lower than that in group B. This suggested that revascularization combined with drug therapy for TAO had a good clinical effect, which can reduce the amputation rate of patients.

TAO is a thrombotic occlusive and inflammatory peripheral arterial disease. Most scholars believe that the occurrence of TAO is caused by the interaction of internal and external factors (26). VEGF is a secreted endothelial cell-specific mitogen which is the most critical cytokine responsible for neovascularization (27). IL-1 is a central mediator that regulates the inflammatory and immune responses in the body and is an important pro-inflammatory factor (28). TNF- $\alpha$ has a direct cytotoxic effect, which can destroy the structure of vascular endothelial cells, leading to vascular endothelial dysfunction, which in turn leads to the secretion of pro-inflammatory factor IL-1 (29). Wan et al (30) reported that postoperative lower extremity symptoms were significantly improved in TAO patients, and VEGF levels were markedly elevated. The combination of VEGF with other growth factors (such as angiopoietin-1, hepatocyte growth factor) may become an alternative strategy to promote neovascular growth. Yong et al (31) reported that cilostazol combined with aspirin can improve the clinical symptoms of patients, and can effectively reduce the level of serum inflammatory factors in patients. Thus, promotion of angiogenesis and inhibition of inflammatory factor levels may be the key to treat TAO. The results of our study showed that serum VEGF levels in both groups increased significantly after treatment, while IL-1 and TNF- $\alpha$ levels declined significantly. After treatment, serum VEGF level in group A was markedly higher than that in the group B, while IL-1 and TNF- $\alpha$ levels were both evidently lower than that in the 
group B. This suggests that promotion of angiogenesis and inhibition of inflammatory factor levels may be one of the therapeutic mechanisms of TAO. Wu et al (32) showed that revascularization can visibly improve the clinical symptoms and dysfunction of patients with TAO. This was probably achieved by inhibiting IL- 6 , IL- 8 and TNF- $\alpha$, and reducing inflammation. Whether to perform revascularization and ischemic staging is one of the factors affecting vascular reocclusion or amputation, which is similar to this study. Other studies have shown that smoking history, ischemic staging and whether vascular reconstruction is performed are the risk factors for amputation in TAO patients. However, Wu et al (32) concluded that smoking history was not related to amputation in TAO patients. This may be due to the fact that the patients in their study were older and had longer smoke history than those used in our study. Amputation of TAO patients often affects their life quality (33). Previously, there have been many studies on the risk factors of amputation in patients with TAO (34-36), but there is no report on whether VEGF, IL-1 and TNF- $\alpha$ levels are risk factors for amputation in patients with TAO before treatment. Results showed that VEGF, IL-1, and TNF- $\alpha$ had a certain diagnostic value for amputation in patients with TAO before treatment, and low concentrations of VEGF and higher concentrations of IL-1 and TNF- $\alpha$ were risk factors for amputation in TAO patients. Therefore, observation of VEGF, IL-1 and TNF- $\alpha$ levels may have predictive value for amputation prognosis of patients with TAO.

This study confirmed the feasibility of revascularization combined with alprostadil and cilostazol in the treatment of TAO, and initially confirmed the predictive value of VEGF, IL-1 and TNF- $\alpha$ in amputation in patients with TAO.

In conclusion, revascularization combined with alprostadil and cilostazol in the treatment of TAO patients had a good clinical efficacy with a possible therapeutic mechanism by upregulating VEGF and inhibiting IL-1, TNF- $\alpha$. Pretreatment serum VEGF, IL-1 and TNF- $\alpha$ had a positive diagnostic value for poor prognosis of patients with amputation, and high concentrations of VEGF and high concentrations of IL-1 and TNF- $\alpha$ are risk factors for amputation in patients with TAO.

\section{Acknowledgements}

Not applicable

\section{Funding}

No funding was received.

\section{Availability of data and materials}

The datasets used and/or analyzed during the current study are available from the corresponding author on reasonable request.

\section{Authors' contributions}

ZFL wrote the manuscript. ZFL and WHW collected and analyzed general data of patients. YWC, SYL and LD were responsible for evaluation of treatment efficacy. YQS, YWB and XJS performed ELISA. All authors read and approved the final manuscript.

\section{Ethics approval and consent to participate}

The study was approved by the Ethics Committee of the First Hospital of Lanzhou University (Lanzhou, China) and informed consents were signed by the patients and/or the guardians.

\section{Patients consent for publication}

Not applicable.

\section{Competing interests}

The authors declare that they have no competing interests.

\section{References}

1. Sun XL, Law BY, de Seabra Rodrigues Dias IR, Mok SW, He YZ and Wong VK: Pathogenesis of thromboangiitis obliterans: Gene polymorphism and immunoregulation of human vascular endothelial cells. Atherosclerosis 265: 258-265, 2017.

2. Rivera-Chavarría IJ and Brenes-Gutiérrez JD: Thromboangiitis obliterans (Buerger's disease). Ann Med Surg (Lond) 7: 79-82, 2016.

3. Neufang A, Vargas-Gomez C, Ewald P, Vitolianos N, Coskun T, Abu-Salim N, Schmiedel R, von Flotow P and Savvidis S: Very distal vein bypass in patients with thromboangiitis obliterans. Vasa 46: 304-309, 2017.

4. Klein-Weigel PF, Köning C, Härtwig A, Krüger K, GutschePetrak B, Dreusicke S, Thieme U, Enke-Melzer K, Urbach B and Kron J: Immunoadsorption in Buerger's disease (thromboangiitis obliterans): A promising therapeutic option: Results of a consecutive patient cohort treated in clinical routine care. Zentralbl Chir 137: 460-465, 2012 (In German).

5. Jiménez-Gallo D, Albarrán-Planelles C, Arjona-Aguilera C, Blanco-Sánchez G, Rodríguez-Mateos ME and LinaresBarrios M: Treatment of thromboangiitis obliterans (Buerger's disease) with high-potency vasodilators. Dermatol Ther (Heidelb) 28: 135-139, 2015.

6. Narváez J, García-Gómez C, Álvarez L, Santo P, Aparicio M, Pascual M, López de Recalde M, Borrell H and Nolla JM: Efficacy of bosentan in patients with refractory thromboangiitis obliterans (Buerger disease): A case series and review of the literature. Medicine (Baltimore) 95: e5511, 2016.

7. Sugimoto M and Komori K: Buerger's disease (thromboangiitis obliterans). In: Systemic Vasculitides: Current Status and Perspectives. Dammacco F (ed). Springer, Switzerland, pp361-376, 2016.

8. Galyfos G, Kerasidis S, Kastrisios G, Giannakakis S, Sachmpazidis I, Anastasiadou C, Geropapas G, Papapetrou A, Papacharalampous $\mathrm{G}$ and Maltezos C: Conservative treatment of patients with thromboangiitis obliterans or cannabis-associated arteritis presenting with critical lower limb ischaemia. Vasa 46: 471-475, 2017.

9. Fazeli B, Dadgar Moghadam M and Niroumand S: How to treat a patient with thromboangiitis obliterans: A systematic review. Ann Vasc Surg 49: 219-228, 2018.

10. Guo J, Guo L, Cui S, Tong Z, Dardik A and Gu Y: Autologous bone marrow-derived mononuclear cell therapy in Chinese patients with critical limb ischemia due to thromboangiitis obliterans: 10-year results. Stem Cell Res Ther 9: 43, 2018.

11. Fazeli B and Rezaee SA: A review on thromboangiitis obliterans pathophysiology: Thrombosis and angiitis, which is to blame? Vascular 19: 141-153, 2011.

12. Huang ZH, Kuo SY, Chiu YH, Chen HC and Lu CC: Treatment of multiple refractory ankle ulcerations in thromboangiitis obliterans: A case report. Medicine (Baltimore) 97: e10798, 2018.

13. Ferrara $\mathrm{N}$ and Adamis AP: Ten years of anti-vascular endothelial growth factor therapy. Nat Rev Drug Discov 15: 385-403, 2016. 
14. Akar AR, İnan MB and Baran C: Thromboangiitis obliterans. Curr Treatm Opt Rheumatol 2: 178-195, 2016.

15. Fazeli B, Rafatpanah H, Ravari H, Farid Hosseini R, Tavakol Afshari J, Hamidi Alamdari D, Valizadeh N, Moheghi N and Rezaee SA: Sera of patients with thromboangiitis obliterans activated cultured human umbilical vein endothelial cells (HUVECs) and changed their adhesive properties. Int J Rheum Dis 17: 106-112, 2014.

16. Nosaka M, Ishida Y,Kimura A, Kuninaka Y, Taruya A, Furuta M, Mukaida N and Kondo T: Contribution of the TNF- $\alpha$ (tumor necrosis factor- $\alpha$ )-TNF-Rp55 (tumor necrosis factor receptor p55) axis in the resolution of venous thrombus. Arterioscler Thromb Vasc Biol 38: 2638-2650, 2018.

17. Shapouri-Moghaddam A, Saeed Modaghegh MH, Rahimi HR, Ehteshamfar SM and Tavakol Afshari J: Molecular mechanisms regulating immune responses in thromboangiitis obliterans: A comprehensive review. Iran J Basic Med Sci 22: 215-224, 2019.

18. Olin JW: Thromboangiitis obliterans: 110 years old and little progress made. J Am Heart Assoc 7: e011214, 2018.

19. Taniguchi T, Higuchi T, Tazaki J, Saito N and Kimura T: Successful percutaneous transcatheter angioplasty of radial artery in thromboangiitis obliterans (Buerger's disease). JACC Cardiovasc Interv 10: e205-e206, 2017.

20. Kim DH, Ko YG, Ahn CM, Shin DH, Kim JS, Kim BK, Choi D, Hong MK and Jang Y: Immediate and late outcomes of endovascular therapy for lower extremity arteries in Buerger disease. J Vasc Surg 67: 1769-1777, 2018.

21. Narváez J, García-Gómez C, Álvarez L, Santo P, Aparicio M, Pascual M, López de Recalde M, Borrell H and Nolla JM: Efficacy of bosentan in patients with refractory thromboangiitis obliterans (Buerger disease): A case series and review of the literature. Medicine (Baltimore) 95: e5511, 2016.

22. Del Conde I and Peña C: Buerger disease (thromboangiitis obliterans). Tech Vasc Interv Radiol 17: 234-240, 2014.

23. Jun HJ: Endovascular revascularization for the obstruction after patch angioplasty in Buerger's disease. Korean J Thorac Cardiovasc Surg 47: 174-177, 2014.

24. Dilege S, Aksoy M, Kayabali M, Genc FA, Senturk M and Baktiroglu S: Vascular reconstruction in Buerger's disease: Is it feasible? Surg Today 32: 1042-1047, 2002.

25. Bozkurt AK, Köksal C, Demirbas MY, Erdoğan A, Rahman A Demirkiliç U, Ustünsoy H, Metin G, Yillik L, Onol H, et al Turkish Buerger's Disease Research Group: A randomized trial of intravenous iloprost (a stable prostacyclin analogue) versus lumbar sympathectomy in the management of Buerger's disease. Int Angiol 25: 162-168, 2006.

26. Fazeli B and Ravari H: Mechanisms of thrombosis, available treatments and management challenges presented by thromboangiitis obliterans. Curr Med Chem 22: 1992-2001, 2015.
27. Campochiaro PA, Khanani A, Singer M, Patel S, Boyer D, Dugel P, Kherani S, Withers B, Gambino L, Peters K, et al; TIME-2 Study Group: Enhanced benefit in diabetic macular edema from AKB-9778 Tie2 activation combined with vascular endothelial growth factor suppression. Ophthalmology 123: 1722-1730, 2016

28. Palomo J, Dietrich D, Martin P, Palmer G and Gabay C: The interleukin (IL)-1 cytokine family - Balance between agonists and antagonists in inflammatory diseases. Cytokine 76: 25-37, 2015.

29. Jain A, Barrile R, van der Meer AD, Mammoto A, Mammoto T, De Ceunynck K, Aisiku O, Otieno MA, Louden CS, Hamilton GA, et al: Primary human lung alveolus-on-a-chip model of intravascular thrombosis for assessment of therapeutics. Clin Pharmacol Ther 103: 332-340, 2018.

30. Wan J, Yang Y, Ma ZH, Sun Y, Liu YQ, Li GJ and Zhang GM: Autologous peripheral blood stem cell transplantation to treat thromboangiitis obliterans: Preliminary results. Eur Rev Med Pharmacol Sci 20: 509-513, 2016

31. Yong J, Zhang S, Gao Y, Guo W, Shi P and Zhou Q: Effects of aspirin combined with cilostazol on thromboangiitis obliterans in diabetic patients. Exp Ther Med 16: 5041-5046, 2018.

32. Wu S, Sun X, Wu W, Shi D and Jiang T: Effect of revascularization on IL- 6 and TNF- $\alpha$ in patients with thromboangiitis obliterans. Exp Ther Med 15: 3947-3951, 2018.

33. Idei N, Soga J, Hata T, Fujii Y, Fujimura N, Mikami S, Maruhashi T, Nishioka K, Hidaka T, Kihara Y, et al: Autologous bone-marrow mononuclear cell implantation reduces long-term major amputation risk in patients with critical limb ischemia: A comparison of atherosclerotic peripheral arterial disease and Buerger disease. Circ Cardiovasc Interv 4: 15-25, 2011.

34. Sambandam MT, Boologapandian V and Amalorpavanathan J: Limb salvage in critical limb ischaemia in thromboangiitis obliterans patients - revascularisation - a study. J Evol Med Dent Sci 7: 3679-3684, 2018.

35. Le Joncour A, Soudet S, Dupont A, Espitia O, Koskas F, Cluzel P, Hatron PY, Emmerich J, Cacoub P, Resche-Rigon M, et al; French Buerger's Network: Long-term outcome and prognostic factors of complications in thromboangiitis obliterans (Buerger's disease): A multicenter study of 224 patients. J Am Heart Assoc 7: e010677, 2018

36. Ye K, Shi H, Qin J, Yin M, Liu X1, Li W1, Jiang M and Lu X: Outcomes of endovascular recanalization versus autogenous venous bypass for thromboangiitis obliterans patients with critical limb ischemia due to tibioperoneal arterial occlusion. J Vasc Surg 66: 1133-1142.e1, 2017.

This work is licensed under a Creative Commons Attribution-NonCommercial-NoDerivatives 4.0 International (CC BY-NC-ND 4.0) License. 